\title{
Pharmacy Technician Workload and Workforce Requirements at MOH Primary Health Care Center during Ten years Mass Gathering Hajj (2006-2015) in Makah Region, Saudi Arabia
}

\author{
Yousef Ahmed Alomi*1, Khairat Alhennawi², Nizar Khayayt ${ }^{3}$ \\ ${ }^{1}$ The Past General Manager of General Administration of Pharmaceutical Care and \\ Head, National Clinical pharmacy, and pharmacy practice and Pharmacy $R \& D$ Administration, \\ Ministry of Health, Riyadh, KSA. \\ ${ }^{2}$ Clinical pharmacy staff, General Administration of Pharmaceutical Care, Ministry of Health, Riyadh, KSA. \\ ${ }^{3}$ Medication Safety Officer General Administration of Pharmaceutical care, Makkah Region, \\ Ministry of Health, Riyadh, KSA.
}

\begin{abstract}
Received: 13 August 2017;
Accepted: 28 September 2017

*Correspondence to:

Dr. Yousef Ahmed Alomi,

The Past General Manager of General Administration of Pharmaceutical Care

Head, National Clinical pharmacy, and pharmacy practice

Head, Pharmacy $R \& D$ Administration Ministry of Health, P.O.BOX 100, Riyadh 11392, Riyadh, Saudi Arabia. Email:yalomi@gmail.com

Copyright: $(\subset$ the author(s),publisher and licensee Indian Academy of Pharmacists. This is an openaccess article distributed under the terms of the Creative Commons Attribution Non-Commercial License, which permits unrestricted non-commercial use, distribution, and reproduction in any medium, provided the original work is properly cited.
\end{abstract}

Publishing Partner : EManuscript [www.emanuscript.in]

\begin{abstract}
Purpose: To explore the pharmacy technician workload analysis and workforce requirements at Ministry of Health Primary health care centers during mass gathering Hajj ten years (2006-2015), Saudi Arabia. Methods: It is a retrospective of ten years (2006-2015) of primary health care center (PCC) pharmacy technician workload during mass gathering Hajj period. The duration of workload collection was 15 days. The pharmacy technician prepares medications and provide pharmaceutical for dispensing through the pharmacist all patients either Pilgrim or not Pilgrim at Makah region. It included Mona holy places hospitals; Arafat holy places hospitals, and Makah city. The workforce requirements calculated based on $\mathrm{MOH}$ workforce standards of primary health care center and the workload drives as central pharmacy technician services, patient specific pharmacy technician activities, and general administration specific pharmacy technician activities. Results: The total number of pilgrims $(1,952,817-3,161,573)$ with average $(2,445,208)$. The total number of prescriptions $(226,824-505,753)$ with average $(411,317)$, it represented (7.12-20.25\%) with average (16.77\%) of all pilgrims. The average number PCC prescription at holy places were $(275,820)$ and $(138,388.40)$ from Makah city. The average number of pharmacy technician needed (12.46FTE) per each PCC at holy places, and (13.99 FTE) per each PCC at Makah city with a total number of pharmacy technician was (26.45 FTE) per each PCC. The grand average number of pharmacist based on $\mathrm{MOH}$ standards for PCC was (1725.86 FTE) while the mean number pharmacy technician needed based on workload was (135.7 FTE) for all PCC. Conclusion: There is very high demand of pharmacy technician workforces during mass gathering Hajj time at primary health care center in Makka region. Targeting to change pharmacy technician workforces $\mathrm{MOH}$ standards requirements improve pharmacy technician services at primary care centers provided to all pilgrims in Makka region, Saudi Arabia.
\end{abstract}

Keyword: pharmacy technician, Workload, Workforces, Primary care center, Mass Gathering, Hajj, Makka, Ministry of Health, Saudi Arabia

\section{INTRODUCTION}

The primary care centers are elementary to build and implement the services to the public to provide fast and quick medical facilities. Also, most of the patient prefer to 
visit primary care center than hospital easy to communicate with the very simple disease in regular days, and it is critical during mass gathering events like for instance Hajj period. The number of primary care center is much more several time than hospital during mass gathering hajj in both Makka and Al-Madina the holy places in the kingdom of Saudi Arabia. ${ }^{[1]}$ Every year the ministry of health arrange temporary and permanent primary care centers during mass gathering Hajj periods with expanding over past several years in Makka region with emphasis on Makka city and holy places. The most efficient and very easy to reach the patient with mass gathering during Hajj with preferable to most patients. The primary care centers operated by medical professionals including a physician, pharmacist, and nurses on regulars days while during mass gathering event other suppressive allied health care professionals including assistant nurses and assistant pharmacist of pharmacy technicians. They help and support pharmacist and clinical with their activities and performance to best medical care to all pilgrims..$^{[2-6]}$ However, the number of pharmacy technician's demand and requirements during mass gathering Hajj period is unknown. Several studies were done to assess mass gathering medicine, the patterns of diseases, and vaccination effectiveness during hajj, but Alomi et al. first studied the national mass gathering pharmaceutical care in Saudi Arabia. ${ }^{[7-11]}$ However, after very extensive literature review and absent of studies discussed the utilization of pharmacy technician at primary care centers mass gathering events but not pharmacy technician at primary care centers. The author not familiar with any study to investigate the workforce of pharmacy technicians during mass gathering hajj time published in Saudi Arabia, or Gulf countries, or even worldwide countries and very seldom to find it. The objective of the study to explore the pharmacy technicians workforce and workload analysis during mass gathering hajj time over past ten years (20062015) in Makka region, Saudi Arabia.

\section{METHODS}

It is a retrospective analysis of ten years (2006-2015) of primary healthcare center (PCC) pharmacy technician workload during mass gathering Hajj period. The duration of workload collection was 15 days. The primary healthcare is the first and the easiest level the patient could reach if they have any health problem. All the data derived from Ministry of Health. Health Statistical Year Books. ${ }^{[12-21]}$ At primary healthcare centers, the patient will receive safe and fast health services such as; medical examination, some blood analysis, and patient follow-up. The patients also will receive their medications with proper counseling and education. ${ }^{[22]}$ There are about 158 primary care centers in Makah region; 46 in Makah city and 112 in holy places (Mina and Arafat). The pharmacy technicians prepare medication and pharmaceuticals for dispensing to all patients (Pilgrim or not Pilgrim). The pharmacy technician at primary care centers may work to help the pharmacist in; administrative affairs unit, total quality unit, medical supply unit, medication safety unit, clinical pharmacy unit, and pharmacy unit but mainly in the pharmacy stores. The pharmacy technician can help the pharmacists there manage patients with acute and chronic common illnesses and provide sufficient care for patients who do not need a hospital. ${ }^{[2]}$ Also, there was extensive literature review search at open date periods with fifty databases. It included the type of studies (meta-analysis, randomized controlled studies, and observational studies, books, reports etc.) in the English language. The search for the term of Hajj and workforce, Hajj and workforce, Hajj and human resources or mass gathering and workforce, mass gathering and workforce, mass gathering and human resources. The search term was in the title and keywords. All setting of patient care services; hospitals inpatient or ambulatory care or community services included. The search included Pharmacy technician. Pharmacist and clinical pharmacist excluded from the study. The location of studies included Saudi Arabia as top propriety if not existed Gulf or Middle East countries included, and if not found overall countries included. The workforce pharmacy technician requirements calculated based on $\mathrm{MOH}$ workforce standards at primary health care center. In addition, the workload drove as central pharmacy services, patient-specific pharmacy activities, and general administration specific pharmacy activities based on the internal literature. ${ }^{[2-4,23-26]}$ The workload calculation based on pharmacy administration database in Makka region with considered that is an average time of Pharmacy technician preparation for dispensing PCC prescription was two minutes and the mean number of medication per each prescription was three minutes. All calculation done used Microsoft Excel version ten.

\section{RESULTS}

The total number of pilgrims was $(1,952,817-3,161,573)$ with average $(2,445,208)$. The total number of prescriptions $(226,824-505,753)$ with average $(411,317)$, it represented (7.12-20.25\%) with average (16.77\%) of all pilgrims. The number of primary care centers in Makah was $(36-46)$ with an average of (41.7), while in holy places there was (80-112) with a mean of (4.9) Primary Care Centers as explored table 1. The average number PCC prescription at holy places were $(275,820)$ and $(138,388.40)$ from Makah city. The average number of PCC order at sacred sites was $(18,388)$ per day 


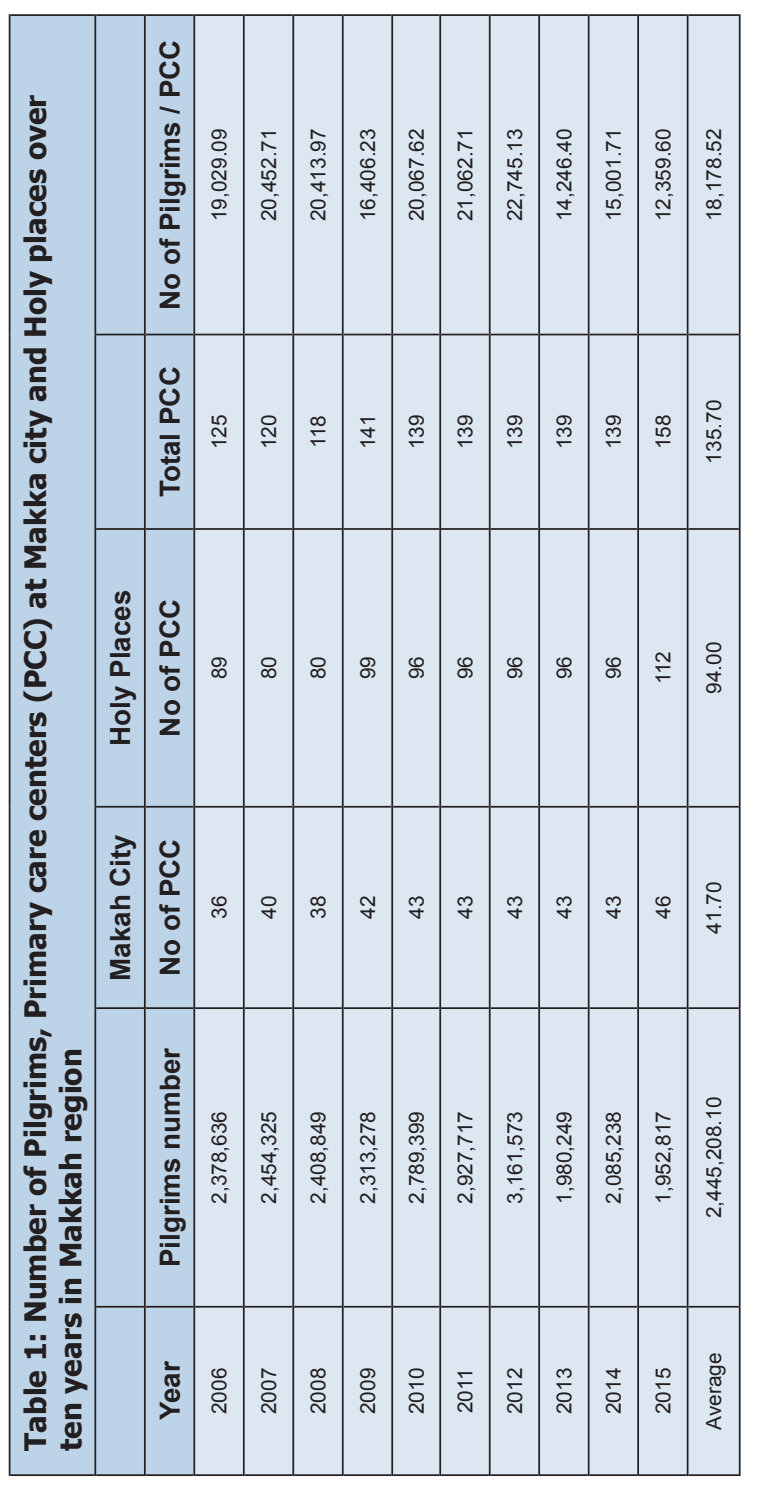

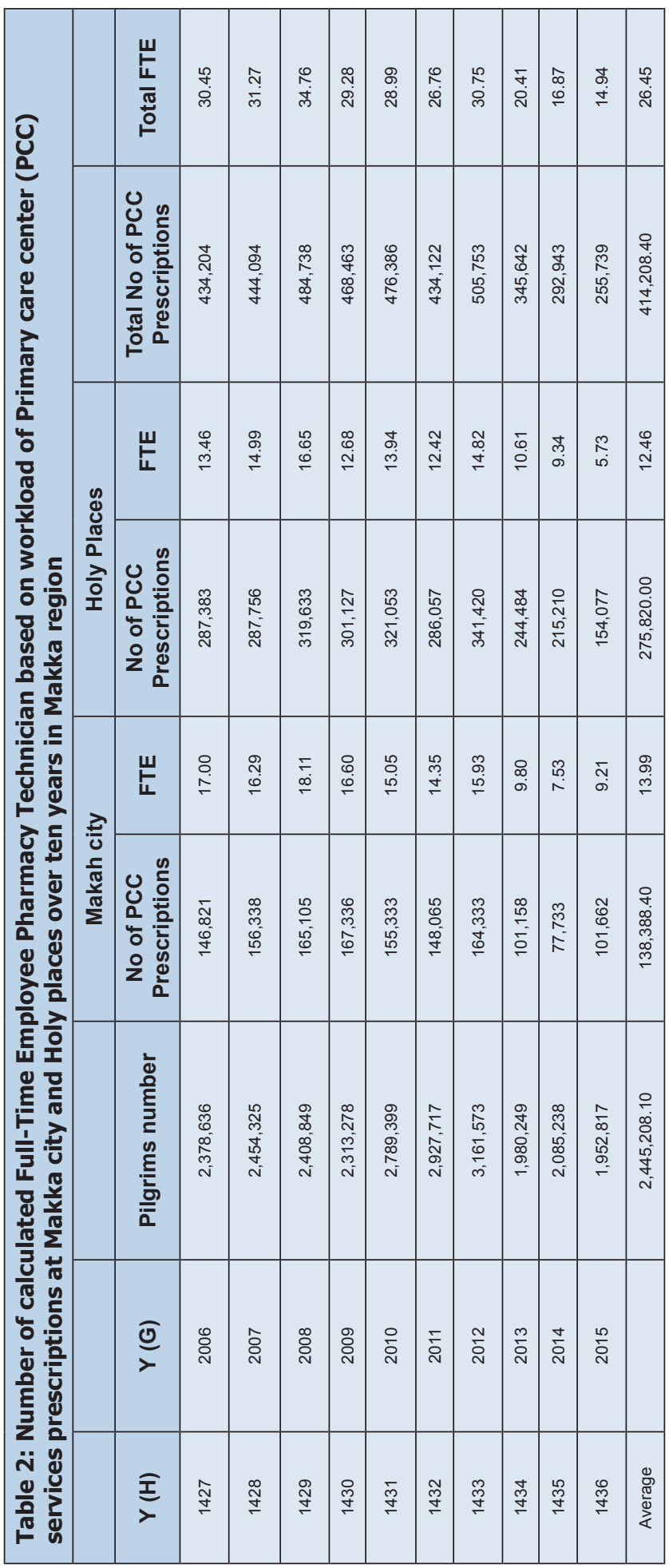




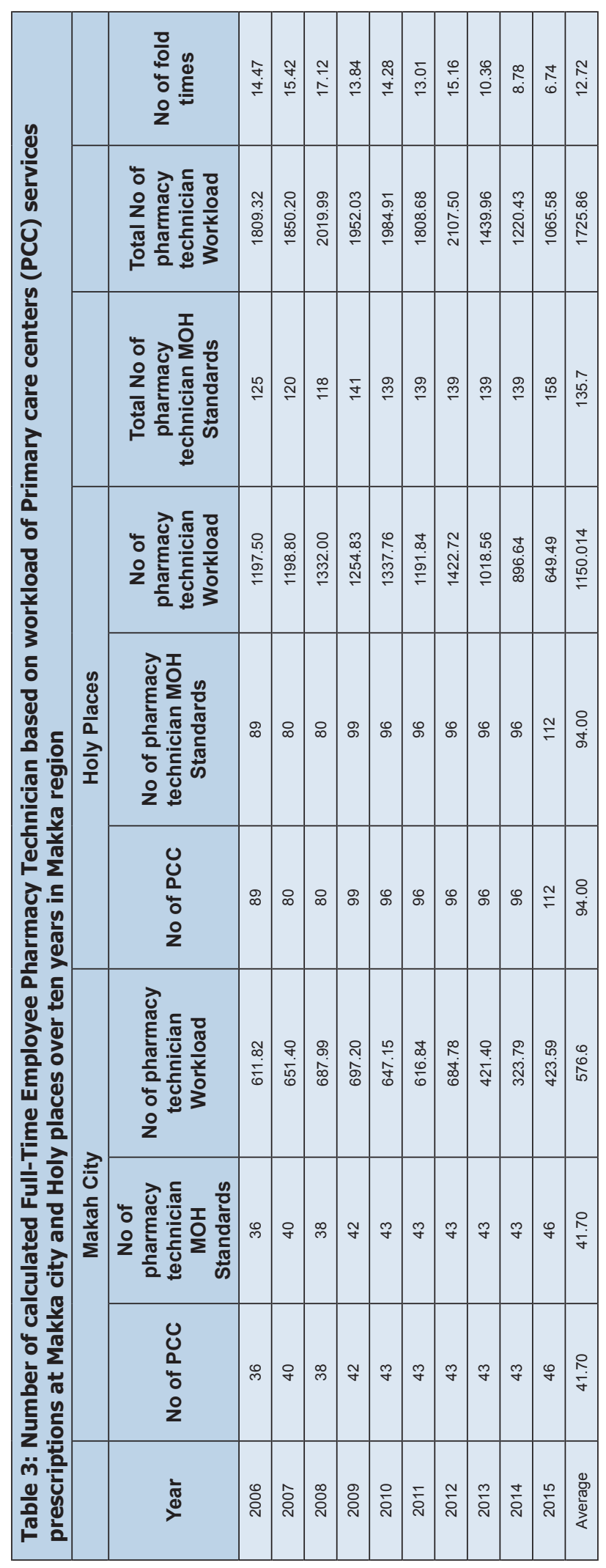

and contained $(55,164)$ medications, while at PCC in Makah city was $(9,255.86)$ prescriptions per day and contained $(27,677.6)$ drugs. The average number of pharmacy technician needed (12.46 FTE) per each PCC at holy places, and (13.99 FTE) per each PCC at Makah city with a total number of pharmacy technician was (26.45 FTE) per each PCC. The grand average number of pharmacy technician based on MOH standards for PCC was (135.7 FTE) while the mean number pharmacy technician needed based on workload was (1725.86 FTE) for all PCC. It is (12.72 fold) more incremental than $\mathrm{MOH}$ pharmacy technician workforce standards per PCC as explored table 2 and table 3. There were no any central pharmacy technician activities and clinical pharmacy technician services or administrative pharmacy technician activities.

\section{DISCUSSION}

The Ministry of health started comprehensive strategic plan through past year with an increased number of primary care centers, organization, and services, with workforces of healthcare providers. ${ }^{[27]}$ The primary care centers have different based on population served. They designed special medication list for the primary care centers. They received all patient with simple and initial of common chronic diseases. The plan covered all Kingdom of Saudi Arabia regions including Makka. The $\mathrm{MOH}$ paid particular attention during mass gathering hajj time at all primary care centers located in Makka region. Most of the work as ambulatory care services and provide emergency services. They are very easy to access them rather than hospitals especially during very crowded area with mass gathering population Hajj time. Over several years of primary care centers improvement, they developed computerized Physician order entry at some them with fully-equipped advance machines ${ }^{[1]}$ One of the major primary care preparation was human resources of health care professional including Physician, pharmacist, and nurses. Also, to supportive personal, as assistant or technician during mass gathering period and pharmacy technician were among them. ${ }^{[1]}$ The number pharmacy technician participated during mass gathering hajj bigger than pharmacist gathers on an annual basis due to a limited number of a pharmacist at $\mathrm{MOH}$ institution. The author investigated the workforces of pharmacy technician and requirements during mass gathering hajj due high demanding. The finding had several times fold incremental demanding as compared to $\mathrm{MOH}$ standards based on workload calculation. The most of the pilgrims visited the primary care centers in Makka city and holy places than hospitals. After very extensive literature review an only limited number of studies discussed utilized 
physician and nurses during mass gathering events but not pharmacy technician at primary care centers. ${ }^{[28-30]}$ There was one study showed based population calculation. ${ }^{[31]}$ The limitation of comparing the results of this study; it was in the population with normal PCCs with normal days nor during the mass gathering event. The authors cannot compare the results of another study because it very had to find looks like the first study about workforces of primary care pharmacy technician during mass gathering Hajj period. These results reflect the real needs of pharmacy technician during Haji period and the shortage present in pharmacy technician staff. The authors suggested updating the pharmacy technician workforces to be twelve per each primary care center during mass gathering Hajj time. The study excluded the pharmacists and clinical pharmacists with another study in the future investigated.

Limitation: Despite the importance of the study, finding the study had several limitations and the author could not control them. The missing of an official of general administration of pharmaceutical care the documentation of pharmacy technician activities at PCC. Also, the type and quantities of medication dispensed through PCCs missed.

Conclusion: The primary health care centers had very high demanding of a pharmacy technician during mass gathering Hajj period in Makka region, Saudi Arabia. Targeting to change $\mathrm{MOH}$ pharmacy technician workforces is required. The requurment of an electronic documentation of pharmacy technician activities. That would reflect actual of pharmacy technician workforces and improve role of pharmacy technician services offered to all pilgrims during mass gathering Hajj time visit Makka region in Saudi Arabia.

\section{ACKNOWLEDGEMENT}

I want to thank all staff at Health affairs administration and pharmaceutical care administration in Makka region for their cooperation.

\section{CONFLICT OF INTEREST}

None

\section{ABBREVIATION USED}

KSA: Kingdom of Saudi Arabia, MOH: Ministry of Health, PCC: Primary care center

\section{REFERENCES}

1. Saudi Ministry of Health. Health Statistical Year Book 2016. Available from: http://www.moh.gov.sa/en/ministry/statistics/book/pages/default.aspx

2. ASHP. Roles and Responsibilities of Pharmacy Technicians. Am J Heal Pharm. 2016;73:928-30.

3. Professional Competencies for Canadian Pharmacists at Entry to Practice. 2007. Available from: http://napra.ca/content_files/files/comp_for_cdn_ pharmacists_at_entrytopractice_march2014_b.pdf

4. Exploring the role of hospital pharmacy technicians and assistants to enhance the delivery of patient centered care. Available from: http://shpa. org.au

5. Mkeresztes J. Role of Pharmacy Technicians in the Development of Clinical Pharmacy. Ann Pharmacother. 2006;40:2015-9.

6. Mabasa VH, Malyuk DL, Tung A, Balen RM, Nicolls TR, Rahiman NL. Using Clinical Pharmacy Support Technicians to Optimize Pharmaceutical Care in the Intensive Care Unit. Can J Hosp Pharm. 2010; 63(1): 41-45.

7. Khan NA, Ishag AM, Ahmad MS, El-Sayed FM, Bachal ZA, Abbas TG. Pattern of medical diseases and determinants of prognosis of hospitalization during 2005 Muslim pilgrimage (Haij) in a tertiary care hospital. A prospective cohort study. Saudi Med J. 2006;27(9):1373-80.

8. Memish ZA, Stephens GM, Steffen R, Ahmed QA. Emergence of medicine for mass gatherings: Lessons from the Hajj. Lancet Infect Dis. 2012;12(1):56-65.

9. Al-Tawfiq JA, Memish ZA. Mass Gatherings and Infectious Diseases. Prevention, Detection, and Control. Infect Dis Clin North Am. 2012;26(3): 726-37.

10. Ahmed Alomi Y, Pharm B, Clin Pharm M. National Mass Gathering Pharmaceutical Care Program at $\mathrm{MOH}$ in Saudi Arabia. J Pharm Pract Community Med. 2016;2(23):102-3.

11. Alomi YA, Zahran R. Self-Assessment of mass gathering (Hajj) pharmaceutical care program in Saudi Arabia. J Pharm Pract Community Med. 2016;2(24):137-43.

12. Saudi Ministry of Health. Health Statistical Year Book 2006; Available from http://www.moh.gov.sa/en/Ministry/Statistics/book/flash/1427/ $\mathrm{MOH}$ _Report_1427.html

13. Saudi Ministry of Health. Health Statistical Year Book 2007; Available from http://www.moh.gov.sa/en/Ministry/Statistics/book/flash/1428/ $\mathrm{MOH}$ _Report_1428.html

14. Saudi Ministry of Health. Health Statistical Year Book 2008. Available from: http://www.moh.gov.sa/en/Ministry/Statistics/book/flash/1429/ $\mathrm{MOH}$ _Report_1429.html

15. Saudi Ministry of Health. Health Statistical Year Book 2009; Available from http://www.moh.gov.sa/en/Ministry/Statistics/book/flash/1430/ $\mathrm{MOH}$ _Report_1430.html

16. Saudi Ministry of Health. Health Statistical Year Book 2010; Available from http://www.moh.gov.sa/en/Ministry/Statistics/book/Pages/default. aspx

17. Saudi Ministry of Health. Health Statistical Year Book 2011. Available from http://www.moh.gov.sa/en/Ministry/Statistics/book/Pages/default.aspx

18. Health Statistical Year Book 2012. Saudi Ministry of Health. Available from: http://www.moh.gov.sa/Ministry/Statistics/book/Documents/1433.pdf

19. Saudi Ministry of Health. Health Statistical Year Book 2013. Available from: http://www.moh.gov.sa/en/Ministry/Statistics/book/Pages/default.aspx

20. Health Statistical Year Book 2014. Saudi Ministry of Health. Available from: http://www.moh.gov.sa/en/Ministry/Statistics/book/Documents/StatisticalBook-for-the-Year-1435.pdf

21. Health Statistical Year Book 2015. Saudi Ministry of Health. Available from: http://www.moh.gov.sa/ministry/statistics/book/pages/default.aspx

22. Alomi YA. National Primary Care Pharmacist Competency System at $\mathrm{MOH}$ in Saudi Arabia. J Pharm Pharm Sci. 2017;1(14):1-5.

23. Alomi YA. Primary Care Center Pharmacy Manpower New Guidelines in Saudi Arabia. J Pharmacol Clin Res. 2016;1(1).

24. Bond C, Raehl C, Franke T. Clinical Pharmacy Services, Pharmacist Staffing, and Drug Costs in United States Hospitals. Pharmacotherapy. 1999;19(12):1354-62. 
25. Bond C, Raehl C, Franke T. Total Cost of Care, and Length of Stay in United States Pharmacy Services and Staffing. Pharmacotherapy. 2001;21(2):129-41.

26. Bond CA, Raehl CL. Clinical pharmacy services, pharmacy staffing, and hospital mortality rates. Pharmacotherapy. 2007;27(4):481-93.

27. Ministry of Health. A Achievements 2013. 1st Ed. Ministry of Health, Saudi Arabia; 2011. 132-135 p. Available from: http://sgsminsk.by/_/media/Global/ Documents/Technical Documents/Technical Datasheets/SGS-PCA-SADatasheet SFDA-A4-EN-11-V2.pdf
28. SandersAb, Criss E, Stecki P, Meislin HWH, Raife J, Allen, et al. An analysis of medical care at mass gatherings. Ann Emerg Med. 1986;15(5):515-9.

29. Smith WP, Wessels V, Naicker D, Leuenberger E, Fuhri P, Wallis LA, et al Development of a mass-gathering medical resource matrix for a developing world scenario. Prehosp Disaster Med. 2010;25(6):547-52.

30. An Introduction to Mass Gatherings Introduction to Mass Gatherings. 2014; Available from: http://www.ceep.ca/publications/Mass Gatherings.pdf

31. Bloom BS. Health manpower planning. Health Serv Res. 1980;15(1):67-8.

Cite this article as: Alomi YA, Alhennawi K, Khayayt N. Pharmacy Technician Workload and Workforce Requirements at MOH Primary Health care center during ten years mass gathering Hajj (2006-2015) in Makah Region, Saudi Arabia. J Pharm Pract Community Med. 2017;3(4s):S95-S100. 